SOCIAL RESEARCH REPORTS

ISSN: 2066-6861 (print), ISSN: 2067-5941 (electronic)

\title{
ASSESSING THE WAY GENDER NORMS AFFECT TEENAGERS' BEHAVIOUR IN THE CONTEXT OF SOCIAL MEDIA
}

\section{Corina-Maricica SESERMAN}

Social Research Reports, 2021, Vol. 13, Issue 1, pp. 38-48

The online version of this article can be found at: www. researchreports.ro

\section{https://doi.org/10.33788/srr13.1.4}

Published by:

Expert Projects Publishing House

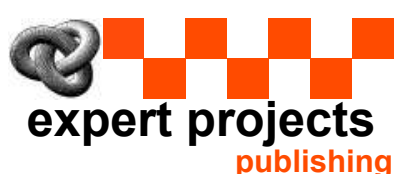

Covered by Index Copernicus International www.indexcopernicus.com

Directory of Open Access Journals www.doaj.org

On behalf of:

Center for Program and Social Development

Aditional services and information about Social Research Reports can be found at: www.researchreports.ro 


\title{
ASSESSING THE WAY GENDER NORMS AFFECT TEENAGERS' BEHAVIOUR IN THE CONTEXT OF SOCIAL MEDIA
}

\author{
Corina-Maricica SESERMAN ${ }^{1}$
}

\begin{abstract}
The internet, together with its associated smart technologies, has a central, and since the SARS-CoV-2 pandemic one might even add, essential position in the fluid functionality of social apparatus. This is apparent on multiple facets, but it has especially impacted the way individuals socialise and present themselves in the online space. Although it has been in use for several decades the way the Internet is perceived has changed significantly as now it has presently become an extension of the social front stage. Through the tools offered by social media platforms, such as Facebook and Instagram, users can carefully construct their own digital versions. These characteristics have proven to be highly attractive to teenagers, as social media platforms offer them the possibility of engaging with their peers, uncover various aspects about the environment outside their familiar space and to create a digital identity. All of these aspects prove to be attractive to them as it caters to their need to seek and to have a sense of empowerment and belonging. Gender plays an important role in the process of developing one's identity and the type of behaviour an individual chooses to present in a social environment, be it digital or otherwise. Previous studies have also pointed out the fact that gender stereotypes and gender norms affect and influence the way individuals perceive others and the type of behaviour they act out. This paper aims to pinpoint a theoretical examination of the way teenagers' behaviour and digital identity on social media platforms is affected by the way people around them look at and perceive gender.
\end{abstract}

Keywords: gender norms, gender identity, teenagers, social media, identity performance

\footnotetext{
1 "Alexandru Ioan Cuza" University from Iasi, Departement of Sociology and Social Work, Iasi, ROMANIA. E-mail: corina.seserman@gmail.com
} 


\section{Introduction}

The impact that smart/digital technologies, together with the internet, had on modern social forms is indisputably tremendous. This has been particularly noticeable during the SARS-CoV-2 pandemic as it pushed all aspects necessary for the function of society in the digital space. At this stage one can argue that the internet has lost its once held sense of novelty or as Adam Tyma states in regards to new media 'it is no longer new. It simply is. Merged ubiquitous converged everywhere' (Tyma, 2015:13). This was mostly accomplished by its overwhelming global reach and the multitude of users it attracted. It has become, as Terry Flew argues, a part of 'everyday reality of media and communication usage, with checking email or browsing the Web being no more novel or significant then turning on the television or making a phone call' (Flew, 2002: 7). Digital technology which offers easy internet access has managed to integrate itself in various devices, such as the smart watches, phones, tablets and laptops. Their mobile quality and their ability to connect with each other while recognizing the one sole user on all devices, has created the seamless surfing from one device to another. In this sense it is postulated that this type of technologies and the features they hold 'feed directly into the performativity of mobile lives' while also facilitating the mobilization of feelings and affect, memories and desires, dreams and anxieties' (Elliott, 2016: 169). Mobilization and accessibility in this sense is what allowed this very complex integration of the digital space in every level of social life and what created the opportunity for the exploration of the various levels of the self. A crucial feature that the virtual space holds is the fact that it allows the possibility of communication and maintaining social relationships through it (Elliott, 2016).

Social media platforms not only play a crucial role in maintaining relationships by offering tools which help ease the process of communication through individuals, but also provide the user with the ability to try one and perform different types of identities or versions of themselves. In this sense this article looks at these types of platforms as being an environment within the digital sphere where users can come together as a group with similar interests where they can share and/or create content, data, forge relationships and activilly communicate, while performing and engaging with their notion of identity. Self-performance and self-expression and construction on social media is done under many aspects through the use of multiple forms of media, but the photograph or better said the selfie is preferred (Ichau et al., 2019). These platforms can appear under different formats such as blogs (Tumbler), interactive multimedia messaging systems (Snapchat), short mobile videos (TikTok), texting (Twitter), video creating and producing (Youtube), streaming (Twitch) and social networking, photo and video sharing (Facebook and Instagram) (Aksoy, 2018). They also provide easy access by being available in a website format, but also as an app for smart mobile devices. Out of all of the platforms presented above it has been shown that Facebook and Instagram are among the most popular to be use in order to engage in self- construction and performance, especially for teenagers (Åberg et al., 2020; Hong et al., 2020; Lee et al., 2020). 
The period of adolescence is seen by researchers as a transition the individual undergoes from childhood to emerging adulthood. It is during this period that teenagers are actively prepared and are made aware about them being members of society and they begin to search for and develop their own interpretation of the world. Concerning this topic Erikson mentioned that this period is critical to one's development as its central focus and concern is identity ontogeny (Erikson, 1968). This process is seen as a period of 'self-identification of goals, values, and beliefs by social psychologists, and its formation is a key development issue for adolescence (Vignoles, Schwartz, \& Luyckx, 2011)' (Xu et al., 2018: 248). It can be assumed that through the social lens, identity is constructed not only upon interactions but also as the 'the intersection of race, class, gender and sexuality' (Lucero, 2017:118). This article looks at the impact the gender norms which exist in the social arena in which teenagers are required to navigate in order to grasp a balanced vision of their social reality. There is a certain curiosity which is explored concerning the impact gender has on teenagers' behaviour in the online space, or more specifically on social media platforms. This paper offers a theoretical perspective and analysis in order to capture the current perspectives of discussions in regards to the subject of gender and teenage online behaviour. The following topics which are discussed capture the theoretical inquiry concerning the definition of gender norms and their role in the process of socialization and identity construction and performance for teenagers. In order to better understand how identity is performed and how youth might play with their gender identity, Goffman's theory of dramaturgy is used.

\section{The effect that gender norms has on identity formation}

Lucero (2017) accentuates in her work that the way in which identities are constructed are through a series of complex technosocial procedures. These techno social procedures are intertwined with different and multiple fields that reside outside of the individual social actor. In other words the development of a person's identity does not occur without outside control and influence, but is impacted by powerful forces which direct the type of performance that can be presented on the plethora of available social arenas both in the virtual and non- virtual space (Lucero, 2017). One of the elements which is used in this creation process is that of gender. The term gender is used and understood in this paper as capturing and distinguishing 'those aspects of male and female roles, behaviours and preferences that were socially constructed rather than a function of biology' (Cislaghi \& Heise, 2020: 411). Social scientists adopt this perspective as it provides a counterargument against the integrated myth that males and females are wholly different due to natural causes and due to this, the difference is indisputable. Various theoretical arguments have been made within sociology in relation to the state of gender and the definition mostly accepted in gender and feminist studies is "that gender is best conceptualised as a social system that apportions resources, roles, power and entitlements according to whether a person or practice is perceived as male or 
female, masculine or feminine (Ridgeway and Correll 2004)' (Cislaghi \& Heise, 2020: 411). In this line of thinking it can be said that norms are just a fragment of the overall gender system which is made out of the roles assigned to genders in society, the process of gender socialization and power relations which occur between genders. Therefore gender norms are seen as social rules which are imposed on individuals since birth and the expectations they must fulfil in order to be seen as integrated members of society.

This sociological perspective of gender was first shaped by the French feminist Simone de Beauvoir who famously wrote in her book The Second Sex the classic phrase: 'One is not born, but rather becomes, a woman' (de Beauvoir, 1949:330). Quote which paved the way in grasping a more complex understanding on gender and its effect it holds on a person's identity. When discussing norms and the formations of the self it is necessary to discuss the concept of gender identity. Therefore, gender identity is an individual's self-conception of being male or female based on his or her association with masculine or feminine gender roles. This type of associative identity is connected to the conceptual framework of what a certain sex category actually means and what kind of person does it make us as a consequence of being a man or a woman. These character features are not present in a baby at birth, but rather they develop and form inner roots throughout its formative years and even well into adulthood. As de Beauvoir noticed, becoming gendered is a complex and unpredictable process. Even if a male sex child (for example) is placed in a highly gendered household and is exposed to content especially aimed at boys and men (such as sports), it is not guaranteed that the child will be identifying with said gender. The socialization processes push the desired expectations on the individual, but that does not mean that the person exposed to them will enact them blindly. Their coming to fruition completely is highly unlikely, but individuals will still hold on to them to a certain level as society tends to hold one accountable on whether they are appropriately feminine or masculine in association with their biological sex. In addition, it is worth mentioning that there are different types of socialization processes, in the sense that through the basic socialization process a child learns what are the laws and social rules of the environment $\mathrm{S} / \mathrm{he}$ is exploring, while interlinked with its gender socialization which contributes to their understanding of social relations and their own self.

Gender socialization is the development and learning of gender roles which is accomplished through the supervision and disciplinarian authority of agencies such as the family, schools and the media. This process can also be seen as a gender norm assimilation and integration in one's daily performance in order to gain the favour of their community. Gender socialization begins as soon as an infant is born. Children are very willing to learn about the world around and therefore they tend to internalize the norms and expectations that correspond to their biological sex. They 'adopt 'sex roles' and the male and female identities (masculinity and femininity) that accompany them' (Giddens A, 2009:623). Gender socialization can be analysed as a two-sided process. The first side represents the target, the subject towards whom socialization is aimed, 'such as a newborn, who encounters the social world through interactions with parents and caretakers' (Wharton, 2005: 31 ). Through these relations and engagement, the child becomes aware of both 
the outside world and of its mechanisms and of his own being within that space. It is quite beguiling that information about gender is something considered very essential in understanding and interacting with each other. This 'reveals just how deeply implicated gender is in the process of becoming human and developing a self' (Wharton, 2005: 31). The other side of the socialization process is the agents who guide and enforce it, such as individuals, groups, and organizations that pass on cultural and social information, who decide what is appropriate and what is not.

We developed distinct social practices that are used as a catalyst that deepen, complicate and even mythologize the distinctions from male and female bodies and their social significance. These social arrangements may not simply focus in a regular fashion on the prevalent bodily differences, but what occurs is that bodies are brought into the social practices arena 'in which our social conduct does something with reproductive difference' (Connell, 2009: 11). In other words, the concept of gender is centered around the reproductive basis of the human species. Within this reproductive arena social practices are being initiated and acted out in a manner that links the biological to social processes. This pinpoints the way society deals with the human body and its places in a community, and it reflects its concerns and involvement within the individual's and the collective's space. Therefore it is worth mentioning that gender is not a structure that is reproduced biologically, but rather it finds its roots in the social sphere where these types of arrangements are constantly shaping the individual's and the group's action. This does not mean that gender arrangements are static. On the contrary, they are under constant reformation and change, as new narratives arrive that push towards new practices and structures. Due to its reach in one's personal life and that of the public, gender as a structure presents itself as being multidimensional. Rather than representing just an element that is essential in the formation of someone's identity, in the analyses of labour division, sexuality or power, gender encompases all of them.

Concerning teenagers' behaviour in the digital space or more specifically on social media it appears that gender norms take an essential position of the types of meanings they deliver in their content and posts. Due to the affordability social media platforms, such as Facebook and Instagram, bring young users in relation to their profiles being personalized to their liking and their timeline being easily catered to help send certain meaning and performances in relation to the self, it is viewed as being highly attractive. This is also caused by the fact that, as Erikson stated, adolescents' main goals during this time is to attain a feeling of emancipation, belonging and to form a positively viewed identity. This process is highly influenced by the gender norms they are accustomed to and it usually is reflected in the content that they post or consume. In other words, through social media profiles, teenagers have "the possibility to create and share content, as well as to interact with other individuals and associate with cultural products and brands which are consistent with one's Self concept' (Manzi et al., 2018: 82). Out of all of the available social media platforms, currently available research seems to suggest that young people tend to have a preference for Instagram (Seserman \& Cojocaru, 2020; Lowe-Calverley et al., 2019; Lee \& Borah 2020). This application 
essentially is a mobile photo-sharing app which offers certain photo and video editing tools, such as filters, that help enhance the messages and meaning the user wants to convey.

Research shows that the youth most often post pictures of themselves, which are carefully thought out and that show parts of the users identity. The photos they post tend to conform to the gender norms of the community in which they socially navigate and through which they perform certain stories or settings which tell a positive story about the users offline life (Lowe-Calverley et al., 2019). A popular form of picture taking which focuses on the individual is the selfie, which during the research conducted by Seserman and Cojocaru (2020) was labeled by the teenage respondents as being overly sexualised, narcissistic and attention seeking. This type of labeling was especially associated with the content posted by girls. While the content posted by boys although was also labeled as being narcissistic it was seen as being a lot more relaxed, goofy and less staged then the one posted by girls. Both the boys and the girls seemed to agree and describe the content created within the overall gender norm system and seemed to try and adhere to its rules. In relation to this Lowe-Calverley et al. (2019) states that teens use Instagram to self promote, engage in social interaction, to document experiences and to express and create the self. She argued that due to these characteristics the behaviour young people present on Instagram cannot be simply called a simple online photo album sharing platform, but rather she sees it as 'a vehicle for social connection, expression, and intimate communication via images' (Lowe-Calverley et al., 2019:2). Because of this the experiences teenagers might have in the digital space might impact them on an emotional level and cause a change in behaviour and self-performance.

The effect gender norms have on teenager's behaviour and gender identity performance within the digital space can also be seen in the way they describe the content created by other users based on their presented gender. This type of attitude was found in the preliminary data presented by Seserman \& Cojocaru (2020) in the article An Exploration of Gender Differences in Teenagers' use, Consumption and Digital Production. Qualitative data was collected through the use of a focus group during which two small Youtube videos were shown as material to start the discussion. One of the videos had a male speaker and content producer while the other had a female and both of them presented the same scientific subject matter. The sample was formed out of teenagers both male and female of the ages between 15-18. After they watched the clips the teens were asked to use three words to describe the content made by the female and another three words to describe the one made by the male. The words they used to describe the female content creator was " unorganized with a script learned by heart', fast paced, thoughtless, nervous, hard to follow, and unattractive. While the one made by the male was characterized as being 'structured, intelligent, researched, unscripted, well spoken, captivating and interesting' (Seserman \& Cojocaru, 2020:241). The respondents were asked that if they had to do a school assignment on the subject presented which one of the two would they trust more and would they use as reference, to which all of them answered that the male content is the one they would use and trust. This segment from the focus group session might indicate that there is a certain double standard when it comes to the way females as professionals are 
seen. This type of theoretical and methodological inquiry also brings into focus Goffman dramaturgical theory.

\section{Dramaturgical theory in relation to gender norms}

Goffman's dramaturgical theory is defined as an active individual who performs in various social contexts $\mathrm{S} /$ he might encounter while being in the continuous presence of other observers, and this event leaves its audience with some sort of impression. When engaging in such a setting, the individual gains the necessary experience which leads to him understanding the cultural rules in the social context he is present in, and to modifying his behavior accordingly. Goffman defines this process as being an impression management (Smith, 2006) which allows the individual to modify their behavior and to control the type of information they choose to disclose. This process can be especially noticed today on social media sites as individuals practice impression management with the way they cater their online content and the messages it sends out concerning their identity. The author also postulates that these elements of performance take place in specific bonded settings and this 'suggested most behavior was not determined by individualspecific stimulus-response patterns but was instead guided by the norms and goals of specific settings' (Hogan, 2010:278). To be specific, Goffman identifies two main settings or stages in which through various forms of interaction, or lack thereof, the individual acts off various versions of their identity. The dichotomous perspective of dramaturgy presents its readers with a front stage and a backstage, which in essence represents two notions that are extracted theatrical terms (Burns, 1992). To put it in simple terms, the front stage represents the place where the audience enjoys the performance of the actor, while the backstage is represented by the place where the actor prepares for his/her performance, as space and time is needed in order to prepare properly for the next show. In other words, the front stage represents the moments when individuals carry out certain social roles in front of other people and they adapt to fit the expected behavior in regards to it. For example, in the current research, the front stage is determined by the social media profile where the teenagers perform their gender identity which they constructed based on the socialization and gender norms they were exposed to, which as Goffman puts it, mirrors the accredited social values of the society in which the performance occurs. While in the backstage the teenager relaxes and engages with another aspect of their identity known only to them, or to a few people who are intimately close. The digital space can also be seen as having two stages as the youth can actively switch between active and passive use. Burnell et al. (2020) defines active use as being the process in which the users actively produce and post content and therefore perform the self they wish to share with others, while the passive use is seen as the moment when the users consume content though scrolling but do not add their own input to it. This theory underlines that teenagers use norms in order to achieve a sense of belonging to their desired group and tweak their performance depending on the feedback they receive from others. Burnell's view also adds that the teens go through these stages in both the digital and the 
offline environment, but it also points out that the behaviour they expose in the online realm does affect the offline environment.

During adolescence individuals adopt and gain different roles which tailor the identity presented to those they meet in the front stage, the behavior also changes depending on whom the individual engages with. Individuals learn and internalise their scripts as they change roles and they assimilate these scripts while being in their backstage. For example, as a highschooler becomes a university student they are forced to adapt, as their status changes, a different script must be learned. The new student knows if $\mathrm{S} / \mathrm{he}$ is respecting the newly assigned script through the feedback received from their audience (Canary et al., 2008). Goffman argues that the various stages on which individual's acts are bounded by space and time and that the 'impression and understanding fostered by the performance will tend to saturate the region and the time span, so that any individual located in this spacetime manifold will be in a position to observe the performance and be guided by the definition of this situation which the performance fosters' (Goffman, 1959:106). This analysis from a temporal and spatial setting point of view, also provides more reasoning from applying Goffman's theory as the theoretical framework as it pinpoints the various identities adolescents might juggle with, depending on the context, space and time they are in. This attitude is also uphold by Hogan (2010) throughout his research of the presentation of self in the age of social media which, similar to Goffman's work, looks at how social actors, while interacting, attempt to control the impression of others regarding themselves and how they pursue to influence this perception in a positive outcome to their advantage. In this work the author also highlights the multitude of strategies that actors employ when they are interacting with others, in order to manage their external image and the resulting impression. In relations to gender norms and the behaviour of teenagers in the digital space Goffman's theory adds as a continuation to de Beauvoir in the sense that it allows the researcher to look at norms as elements which are used by the social actor in order to achieve a convincing and appreciated performance. Rather than having these norms truly internalised, when performing on the front stage, be it in the offline or the online space, individuals will adapt and showcase a behaviour which falls in the borders accepted by the norm.

\section{Media representations and setting gender norms within teenage identity}

Furthering our understanding of gender and new media is of great significance because they are factors which are an intrinsic part of what constitutes one's identity, and it helps us understand the younger generations and their view on the world. Research on gender is relevant because its findings are essential in the 'fields of stratification, politics and elite studies' (Puwar N, 1997:12). Taking into consideration Goffman's theory during the socialization period when children collect information about the world and the type of behaviour they should adopt it is obvious that a number of stimuli, such as mass media will have an impact on how they perceive and interpret gender norms. In 2016, National Geographic 
uploaded on Youtube a clip entitled 'Hear Kids' Honest Opinions on Being a Boy or Girl Around the World' that explores the 'way gender shapes our lives and experiences and the ongoing cultural conversation surrounding the spectrum of gender identity' (Nichols J M, 2017). The video presents nine year old boys and girls from different countries, such as USA, India, Brazil, Canada, China, Gaza Strip, Kenya and Israel, who are telling their view on gender and the challenges that come with being a boy or a girl within their respective cultures. They were asked what was the best thing about being a boy or a girl to which their answers alternated depending on the country they were from. For example, the children from Kenya have a more biological view on determining gender roles and more worried about fulfilling their basic needs, such as food. Another thing that stands out in the video is that most of the girl participants feel mistreated and unheard while the boys are content with their gender role. This enforces the statement that children internalize the positive and negative stereotypes and norms related to gender.

Research conducted by Wright (2018) presents data which shows that although the internet promised more freedom of gender identity expression due to the way it has evolved, it has also made it impossible to achieve that goal. The internet has integrated the gender and social norms that the offline environment holds and through sites such as Facebook, users create carefully curated versions of their offline selves. Wright argues that when it comes to teenager's behaviour on social media platforms such as Instagram or Facebook, follows Goffmans's dramaturgical theory. The first outlook in Wright's research was to examine the role of family, friends and media on the prosocial or aggressive behavior of teenagers in both the online and offline space. This perspective plays off similar to Endendijk et al. (2019) as both studies have managed to highlight trends and attitudes towards gender identity in the online and offline space and how it is managed through the criteria set by those around them. Through the fear of being shunned or outcasts, teenagers partake in impression management in order to adopt a pleasing front stage self. The second aspect explored in this research is the investigation of 'gender as a moderation in these relationships because research findings suggest that girls are more likely to engage in relational aggression and prosocial behaviors (Crick \& Grotpeter, 1995)' (Wright: 2018:5). She analysed gender differences in behavior in the online and offline, especially exploring adolescent engagement regarding prosocial and aggressive actions. Both Wright (2018) and Endendijk et al. (2019) results validated their hypotheses in the sense that the people who have an impact on a person's socialization process, also have an impact on their impression management of gender identity within the frontage.

\section{Conclusion}

Research shows that out of all of the age groups teenagers are the most actively connected and engaged within the digital space. From the multiple technological devices they own to the high digital literacy they possess, teens seamlessly engage with multiple social media platforms and applications. The experiences they gather in the offline and online realm affect and influence one another, which 
leads to modifications to their performance of self in both realms (Wright, 2018). This implies that the gender norms they are exposed to from a young age, be it through their familial environment or from mass media, not only has an impact on their behaviour through the process of socialization, but it also has an impact on their views and interpretation of the world and society overall. Wright also states that in her research it was uncovered that teens presented similar behaviours in the online realm, on social media platforms, to the one shown in the offline interactions and relationships. It was also pointed out that the opinion and the norms imposed by peers are deemed important, suggesting that peer conformity is seen as a paramount aspect. Therefore when engaging either on social media or in face-to-face interactions, the youth perform in the front stage with behaviours and a gender identity which conforms to the norms accepted by and caused by the pressure of their peer group and the other important members, such as family, teachers or others figure with authority.

\section{References}

Åberg, E. \& Koivula, A. \& Kukkonen, I. (2019). A feminine burden of perfection? Appearance-related pressures on social networking sites. Telematics and Informatics, 46, 101319. DOI: 10.1016/j.tele.2019.101319.

Aksoy, M. (2018). A Qualitative Study on the Reasons for Social Media Addiction. European Journal of Educational Research, 7, 861-865.

Burnell, K, Ackerman, RA, Meter D.J, Ehrenreich, S.E, \& Underwood, M.K. (2019). Self-Absorbed and Socially (Network) Engaged: Narcissistic Traits and Social Networking Site Use. Journal of Research in Personality, 84, 103898. DOI: 10.1016/j.jp. 2019.103898.

Burns, T. (1992). Erving Goffman. London: Routledge.

Canary, D., Cody, A. \& Manusov, V. (2008) Interpersonal Communication 4th ed. New York: Bedford/St. Martin's.

Cislaghi, B \& Heise L (2020). Gender norms and social norms: differences, similarities and why they matter in prevention science. Sociology of Health \& Illness, 42(2), 404-422. DOI: 10.1111/1467-9566.13008.

Connell, R.W. (2009). Gender in World Perspective. Cambridge: Polity Press.

De Beauvoir, S. (1949) .The Second Sex. New York: Vintage Books.

Elliott, A. (2016). Identity troubles: An introduction. New York: Routledge, Taylor \& Francis Group.

Endendijk, J.J., Andrews, N., England, D., \& Martin, C. (2019). Gender-identity typologies are related to gender-typing, friendships, and social-emotional adjustment in Dutch emerging adults. International Journal of Behavioral Development, 43(4), 322-333. DOI: $10.1177 / 0165025418820686$.

Erikson, E.H. (1968). Identity, youth, and crisis. New York: Norton.

Flew, T. (2002). New Media. Second Edition.Oxford: Oxford University Press.

Giddens, A. (2009) Sociology. $6^{\text {th }}$ Edition. Cambridge: Polity Press.

Goffman, E. (1956). The Presentation of Self in Everyday Life. New York: Doubleday. Hogan, B. (2010). The Presentation of Self in the Age of Social Media: Distinguishing Performances and Exhibitions Online. Bulletin of Science, Technology \& Society, 30(6), 377-386. 
Hong, S., Jahng, R., Lee, N., \& Wise, K. (2019). Do you filter who you are? : Excessive self-presentation, social cues, and user evaluations of Instagram selfies. Computers in Human Behavior, 104. 106159. DOI: 10.1016/j.chb.2019.106159.

Ichau, E., Frissen, T., \& d' Haenens, L. (2019). From \#Selfie to \#Edgy. Hashtag Networks and Images Associated with the Hashtag \#Jews on Instagram. Telematics and Informatics, 101275. DOI: 10.1016/j.tele.2019.101275.

Lee, D.K.L., \& Borah, P. (2019). Self-presentation on Instagram and friendship development among young adults: A moderated mediation model of media richness, perceived functionality, and openness. Computers in Human Behavior, 103, 57-66. DOI: 10.1016/j.chb.2019.09.017.

Lowe-Calverley, E. \& Grieve, R. \& Padgett, C. (2019). A Risky Investment? Examining the Outcomes of Emotional Investment in Instagram. Telematics and Informatics, 45, 101299. DOI: 10.1016/j.tele.2019.101299.

Lucero, L. (2017). Safe spaces in online places: social media and LGBTQyouth. Multicultural Education Review, 9(2), 117-128. DOI: 10.1080/2005615X.2017.1313482.

Manzi, C., Coen, S., Regalia, C., Yévenes, A.M., Giuliani, C., \& Vignoles, V.L. (2018). Being in the Social: A cross-cultural and cross-generational study on identity processes related to Facebook use. Computers in Human Behavior, 80, 81-87. DOI: 10.1016/j.chb.2017.10.046.

National Geographic (2016). https:/www.youtube.com/watch?v=2B3ea7IGwLA. Accessed on the 09.12.2020

Nichols, J. M. (2017). https://www.huffingtonpost.com/entry/nat-geo-gender-revolution us_5898a54ce4b0c1284f2710c4. Accessed on 09.12.2020

Puwar, N. (1997) Reflexions on Interviewing Women MPs. Sociological Research Online, 2(1), 82-91. DOI: $10.5153 /$ sro.19.

Seserman, C.M. \& Cojocaru, D. (2020). An Exploration of Gender Differences in Teenagers' use, Consumption and Digital Production. NORDSCI, 1(3), 235-254.

Smith, G. (2006). Erving Goffman. Oxon: Routledge.

Tyma, A.W. (2015). I am you and you are we and we are all . . me? . In: A Herbig, A.F. Herrmann, \& A.W. Tyma (eds.) Beyond New Media. Discourse and Critique in a Polymediated Age. London: Lexington Books, pp. 1-15.

Wharton A (2005). The Sociology of Gender. An Introduction to Theory and Research. Blackwell Publishing. USA.

Wright, M.F. (2018). Popularity and Social Preference Pressure From Parents, Friends, and the Media: Linkages to Aggressive and Prosocial Behaviors. Youth \& Society, 52(3), 332-348. DOI: 10.1177/0044118X18773222.

Xu, H. \& Yang, M. (2017). Development of Adolescent Moral and Civic Identity through Community Service: A Qualitative Study in Hong Kong. Journal of Adolescent Research, 33, 1-26. DOI: 10.1177/0743558417698570. 